\title{
The role of cancer-derived microRNAs in cancer immune escape
}

\author{
Ming $\mathrm{Yi}^{1}$, Linping $X \mathrm{u}^{2}$, Ying Jiao ${ }^{1}$, Suxia $\mathrm{LuO}^{2}$, Anping $\mathrm{Li}^{2}$ and Kongming $\mathrm{Wu}^{1,2^{*}}$
}

\begin{abstract}
During malignant transformation, accumulated somatic mutations endow cancer cells with increased invasiveness and immunogenicity. Under selective pressure, these highly immunogenic cancer cells develop multiple strategies to evade immune attack. It has been well established that cancer cells could downregulate the expression of major histocompatibility complex, acquire alterations in interferon pathway, and upregulate the activities of immune checkpoint pathways. Besides, cancer cells secret numerous cytokines, exosomes, and microvesicles to regulate the functions and abundances of components in the tumor microenvironment including immune effector cells and professional antigen presentation cells. As the vital determinant of post-transcriptional regulation, microRNAs (miRNAs) not only participate in cancer initiation and progression but also regulate anti-cancer immune response. For instance, some miRNAs affect cancer immune surveillance and immune escape by interfering the expression of immune attack-associated molecules. A growing body of evidence indicated that cancer-derived immune modulatory miRNAs might be promising targets to counteract cancer immune escape. In this review, we summarized the role of some miRNAs in cancer immune escape and discussed their potential clinical application as treatment targets.
\end{abstract}

Keywords: microRNA, Cancer immune surveillance, Immune escape, Immunotherapy, Tumor microenvironment, Exosome

\section{Background}

Robust anti-cancer immune response consists of a series of stepwise immune events including the release of cancer-associated antigens, the processing and presentation of antigen presentation cells (APCs), the priming and activation of naïve $\mathrm{T}$ cells, the trafficking and migration of activated $\mathrm{T}$ cells, and the tumor-killing activity of effector cells $[1,2]$. Actually, the anti-cancer immune response is a highly complex process which could be strengthened or weakened by multiple factors such as immune editing, transforming growth factor- $\beta$ (TGF- $\beta$ ) signaling, and immune checkpoints [3-5]. The balance between immunostimulatory and -inhibitory factors is crucial to maintain the immune homeostasis of host and clear the cancerderived materials [6]. However, some immunosuppressive factors could be hijacked by cancer cells to evade immune attack. With the advancement of cancer immunology, it

\footnotetext{
* Correspondence: wukm_lab@163.com

${ }^{1}$ Department of Oncology, Tongji Hospital of Tongji Medical College, Huazhong University of Science and Technology, Wuhan 430030, China ${ }^{2}$ Department of Medical Oncology, The Affiliated Cancer Hospital of Zhengzhou University \& Henan Cancer Hospital, Zhengzhou 450008, China
}

has been realized that these immune rheostats might be ideal targets for cancer immunotherapy [7]. In the last decade, the application of immune checkpoint inhibitors greatly propelled the development of cancer therapeutics [8-10]. Blocking immune checkpoint-associated pathways effectively reactivates exhausted effector cells to eliminate cancer cells.

For some patients, the undermined cytotoxicity of effector cells is not the only rate-limiting step of eliminating cancer cells. In these patients, alterations in some upstream events in cancer-immunity cycle such as the recognition of cancer antigens, the functions of APCs, and the infiltration of $\mathrm{T}$ cells hamper cancer immune clearance as well $[11,12]$. Additionally, more and more studies demonstrated that cancer-derived microRNAs (miRNAs) are closely implicated in the formation of the immunosuppressive tumor microenvironment, disabled effector cells, as well as downregulated cancer immunogenicity $[13,14]$.

miRNAs are a class of small, non-coding, single-strand RNAs which could silence target mRNAs by binding to 
corresponding 3 '-untranslated region (3'-UTR) or open reading frame [15]. It is well documented that miRNAs participate in various physiological and pathological processes including immune defense, immune surveillance, immune homeostasis, as well as carcinogenesis [16-20]. Some specific miRNA patterns are highly correlated with cancer initiation, progression, and drug resistance [21, 22]. Notably, miRNAs could mediate the intercellular communication through being packed into exosomes or microvesicles [23]. As the vital post-transcriptional regulators, some immune modulatory miRNAs affect the expression of a broad range of immunity-associated genes in both cancer cells and tumor infiltrating lymphocytes (TILs) [24].

\section{Cancer immune escape}

Although most patients have an intact immune system, some malignant cells could survive from immune attack and develop into clinically overt cancers [5]. Under the selective pressure of immune surveillance, cancer cells with high immunogenicity are preferentially eliminated by effector cells [25]. Eventually, cancer cells with weak immunogenicity escape immune clearance and become the predominant subpopulations [26]. The loss of immunoediting-mediated immunogenicity is a vital factor for cancer immune evasion. Moreover, other approaches could be utilized by cancer cells to produce immune evasion, such as inducing regulatory immune cells, acquiring disable antigen presentation machinery, upregulating immune checkpoints, and generating immunosuppressive microenvironment (Fig. 1) [27].

\section{Regulatory immune cells}

Regulatory $\mathrm{T}$ cell (Treg) is an immunosuppressive class of $\mathrm{CD}^{+}{ }^{+} \mathrm{T}$ cells [28]. In the tumor microenvironment, hyperactive Tregs could inhibit the tumor-killing activity of effector cells by secreting cytokines such as interleukin-10 (IL-10) and TGF- $\beta$ [29]. Besides, Tregs promote cancer immune evasion by consuming IL-2 and upregulating the expression of multiple immune checkpoints including PD-L1, CTLA-4, T cell immunoglobulin and mucin domain-containing protein 3 (TIM-3), Vdomain Ig suppressor of $\mathrm{T}$ cell activation (VISTA), as well as T-cell immunoreceptor with Ig and ITIM domains (TIGIT) [30-33]. It has been recognized that Tregs plays an indispensable role in ICI resistance at the present stage [34]. Similarly to Tregs, a subset of B cells are identified as immune inhibitory cells which are termed Bregs [35]. Bregs could inhibit inflammation response by increasing the generation of PD-L1 and cytokines such as IL-10 [36, 37].

Myeloid-derived suppressor cells (MDSCs) are a heterogeneous class of myeloid cell precursors which are halted at different stages of differentiation [38].
Abundant MDSCs in tumors induce cell cycle arrest of $\mathrm{T}$ cells via upregulating inducible nitric oxide synthase (iNOS) and arginase-1 (Arg1) [39]. Besides, MDSCs participate in oxidative stress and generate peroxynitrite which eventually blocks $T$ cell activation [40]. Some MDSCs-derived materials such as IL-10, Arg1, and TGF- $\beta$ could modulate the ratio of regulatory immune cells and effector cells [39]. Moreover, a specific phenotype of tumor-associated macrophages (TAMs), M2-type macrophages undermine anti-cancer immune response and promote immune evasion by anti-inflammation cytokines and immune checkpoint-associated pathways [41].

\section{Disable antigen processing and presentation of cancer cells}

The cytotoxicity of cancer-specific effector cells is highly dependent on antigens expressed on cancer cells. Cancer cells tend to harbor alterations in antigen processing machinery (APM), which result in the loss of tumorassociated antigens (TAAs) and neoantigens [5]. Mutations in major histocompatibility complex class I (MHC-I), proteasome subunits latent membrane protein (LMP), as well as transporter associated with antigen processing (TAP) reduce the presentation of recognizable targets on cancer cells [42]. As a result, cancer cells exhibiting low immunogenicity are prone to survive from immune attack.

\section{Immune inhibitory cytokines and immune checkpoints}

Tumor-derived cytokines especially TGF- $\beta$ remarkably reshape the tumor immune microenvironment. This immunosuppressive cytokine repertoire inhibits the functions of multiple effector cells, induces the differentiation of regulatory cells, and impedes the infiltration of $T$ cells $[43,44]$. In addition, overexpressed immune checkpoints or their ligands such as PD-L1 on cancer cells promote the formation of exhausted TILs [45]. Moreover, some cancer cell-derived metabolites including indoleamine 2, 3-dioxygenase (IDO), arginase, and inhibitor of nuclear factor kappa-B kinase are greatly related to immune resistance in tumor as well [46-48].

\section{The role of miRNAs in cancer immune evasion}

Apart from acting as tumor promoters or suppressors, it has been revealed that a growing body of miRNAs could regulate cancer immune surveillance and escape [49]. A panel of miRNAs protect cancer cells from immune clearance by decreasing the immunogenicity of cancer cells and downregulating the magnitude of anti-cancer immune response (Fig. 2). Simultaneously, another group of miRNAs strengthen anti-cancer immune clearance. These immune modulatory miRNAs are termed im-miRNAs [50]. Cancer cell-derived im-miRNAs not only target themselves but also broadly regulate various immune components including MDSCs, Tregs, DCs, 


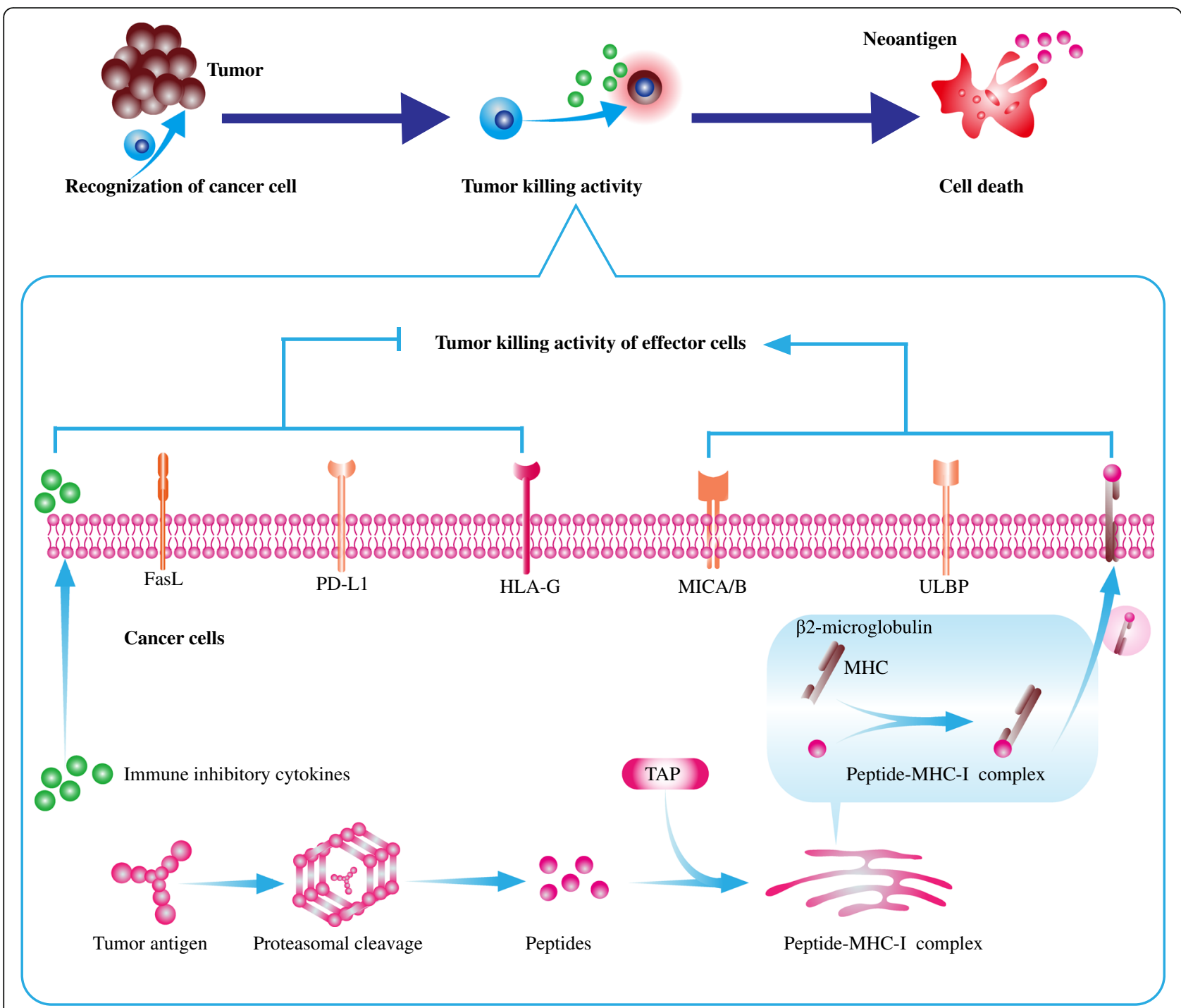

Fig. 1 The mechanisms by which cancer cells escape from immune attack of immune effector cells. Firstly, tumor-derived cytokines especially TGF- $\beta$ remarkably reshape the tumor immune microenvironment. This immunosuppressive cytokine repertoire inhibits the functions of multiple effector cells, induces the differentiation of regulatory cells, and impedes the infiltration of T cells. Secondly, overexpressed immune checkpoints or their ligands such as PD-L1 on cancer cells promote the formation of exhausted TILs. Thirdly, cancer cells tend to harbor alterations in antigen processing machinery, which result in the loss of tumor-associated antigens and neoantigens. Mutations in major histocompatibility complex class I (MHC-I), proteasome subunits latent membrane protein, as well as transporter associated with antigen processing reduce the presentation of recognizable targets on cancer cells. Fourthly, overexpressed HLA-G on cancer cells binds to the inhibitory receptors on effector cells such as CTLS and NKs, leading to the suppression of the cytotoxic activities of these effector cells. Lastly, cancer cells could escape immune attack by downregulating NKG2D ligands including MICA, MICB, and UL16-binding protein. TAP transporter associated with antigen processing, MHC-I major histocompatibility complex class I, MICA/B MHC-I chain-related molecules A/B, IDO indoleamine 2, 3-dioxygenase, ULBP

UL16-binding protein

NKs, as well as cytotoxic T lymphocytes (CTLs) via intercellular communication (e.g., exosomes and microvesicles) $[24,51,52]$.

\section{The miRNAs regulating cancer antigen processing and presentation}

Some im-miRNAs disturb antigen processing and presentation by targeting one or multiple components of APM and MHC-I molecules in cancer cells (Table 1).
Specifically speaking, in nasopharyngeal cancer cells, the results of microarray profiles indicated that miR-9 could target several APM components including TAP1, LMP8 (also termed PSMB8), LMP9 (PSMB9), LMP10 (PSMB10), and $\beta 2$-microglobulin [53]. Besides, miR-9 significantly downregulates MHC-I molecules including human leukocyte antigen-B (HLA-B), HLA-C, HLA-F, and HLA-H [53]. The overexpression of miR-9 in multiple cancers such as cervical cancer, non-small cell lung 


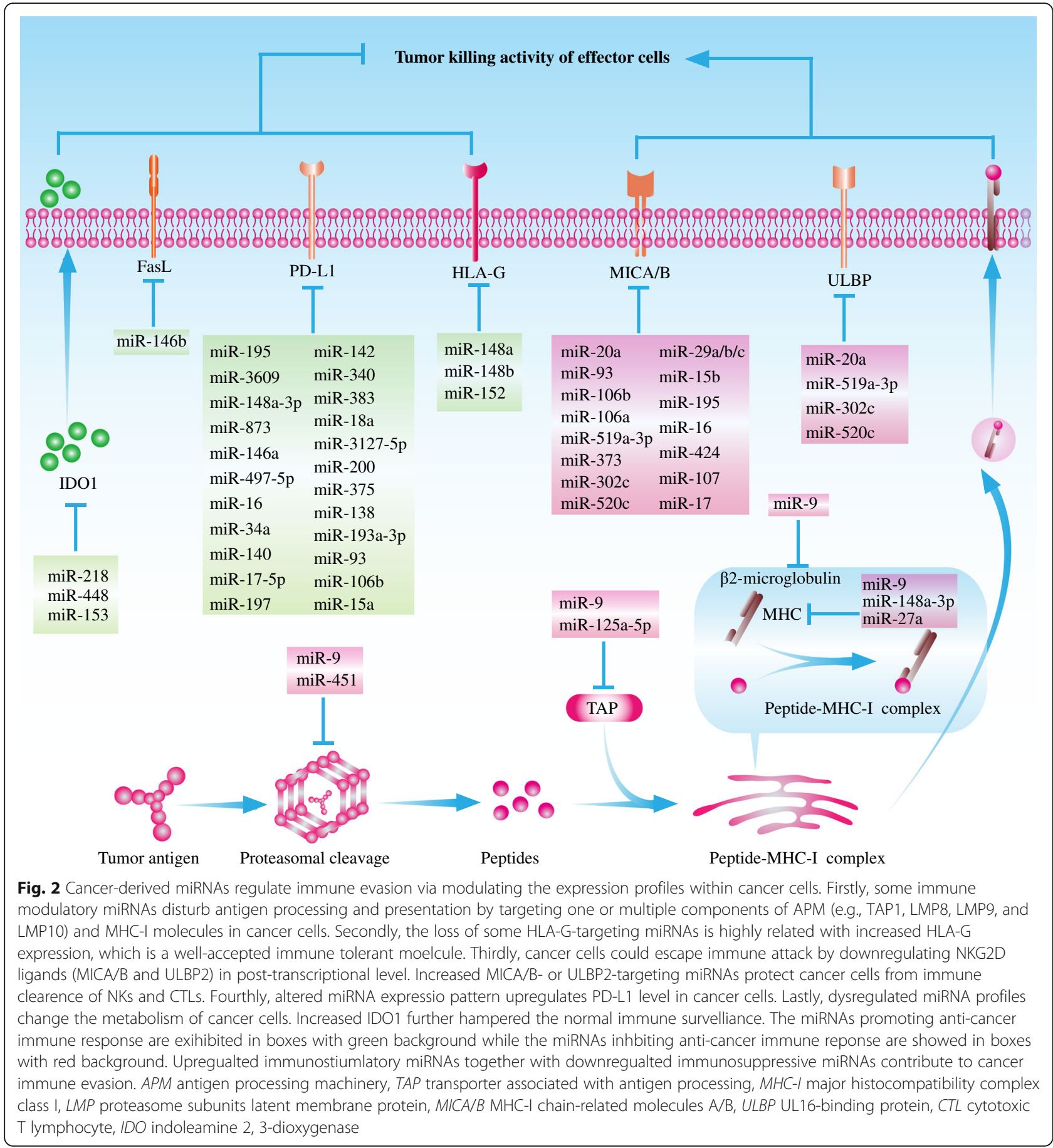

cancer (NSCLC), and glioma might contribute to enhanced immune tolerance in the tumor microenvironment [57-59]. Meanwhile, some endoplasmic reticulum stress-associated miRNAs such as miR-346 regulates immune response by directly targeting TAP1 or indirectly suppressing the expression of MHC-I molecules and interferon (IFN) signaling pathway [60].

Similarly, in esophageal adenocarcinoma cells, it has been verified that miR-125a-5p could bind to the 3'-
UTR of TAP2 mRNA [54]. Also, it was detected that the 3'-UTR of HLA-A, HLA-B, and HLA-C mRNAs had the binding site for miR-148a-3p [54]. Meantime, the results of proteomic screening suggested that miR-27a promoted cancer progression by decreasing MHC-I expression on cell surface, inhibiting $\mathrm{T}$ cell infiltration and cytotoxic activities [56]. This miR-27a-induced MHC-I downregulation was dependent on calreticulin suppression [56]. 
Table 1 The miRNAs regulating cancer antigen processing and presentation

\begin{tabular}{llll}
\hline Targets of miRNAs & miRNAs & Cancer cell types & Ref. \\
\hline TAP1 & miR-9 & Nasopharyngeal cancer & {$[53]$} \\
TAP2 & miR-125a-5p & Esophageal adenocarcinoma & {$[54]$} \\
LMP8 & miR-9 & Nasopharyngeal cancer & {$[53]$} \\
& miR-451 & Lung cancer & {$[55]$} \\
LMP9 & miR-9 & Nasopharyngeal cancer & {$[53]$} \\
LMP10 & miR-9 & Nasopharyngeal cancer & {$[53]$} \\
MHC-I & miR-9 & Nasopharyngeal cancer & {$[53]$} \\
& miR-148a-3p & Esophageal adenocarcinoma & {$[54]$} \\
& miR-27a & Colorectal cancer & {$[56]$} \\
B2-microglobulin & miR-9 & Nasopharyngeal cancer & {$[53]$} \\
\hline
\end{tabular}

TAP transporter associated with antigen processing, LMP proteasome subunits latent membrane protein, $M H C-I$ major histocompatibility complex class I

\section{HLA-G-targeting miRNAs}

As a non-classic MHC-I molecule, HLA-G was initially found to maintain fetal-maternal tolerance [61]. This immune inhibitory function of HLA-G could be hijacked by cancer cells to escape immune attack [62]. Overexpressed HLA-G on cancer cells binds to the inhibitory receptors on effector cells such as CTLs and NKs, leading to the suppression of the cytotoxic activities of these effector cells [62]. Actually, it has been found that HLA$\mathrm{G}$ expression was aberrantly elevated in multiple cancers including melanoma, breast cancer, colorectal cancer, lung cancer, gastric cancer, hepatocellular carcinoma, and endometrial carcinoma $[63,64]$.

In cancer cells, the increased HLA-G expression is closely correlated with the loss of some HLA-Gtargeting miRNAs. Specifically, several members of miR148 family such as miR-148a, miR-148b, and miR-152 could downregulate HLA-G expression [65-67]. In breast cancer cells, it was observed that oncogenic estrogenic G-protein-coupled estrogen receptor-1 (GPER) signaling pathway decreased downstream miR-148a level, further contributing to cancer immune evasion [68]. Additionally, miR-133a was verified as a vital mediator in maintaining peripheral immune tolerance by targeting HLA-G [69].

\section{The MHC-I chain-related molecules A/B and miRNAs}

The oncogenically transformed cells are susceptible to expressing a series of stress-induced ligands including MICA, MICB, and UL16-binding protein (ULBP) [70$72]$. These ligands could be recognized by NKG2D on NKs and CTLs [70]. Intact NKG2D axis is an important signaling pathway to maintain cancer immune surveillance [73]. However, cancer cells could escape immune attack by downregulating NKG2D ligands in posttranscriptional level. So far, numerous miRNAs are portrayed as the modulators of NKG2D ligands (Table 2).
Table 2 The miRNA regulating NKG2D ligands

\begin{tabular}{|c|c|c|c|}
\hline $\begin{array}{l}\text { The targets } \\
\text { of miRNAs }\end{array}$ & miRNAs & Cancer cell types & Ref. \\
\hline \multirow[t]{14}{*}{ MICA } & \multirow[t]{5}{*}{ miR-20a } & Ovarian cancer & {$[74]$} \\
\hline & & Hepatocellular carcinoma & {$[75,76]$} \\
\hline & & Breast cancer & {$[77]$} \\
\hline & & Colorectal cancer & [78] \\
\hline & & Gastric cancer & [79] \\
\hline & miR-93 & Hepatocellular carcinoma & {$[76,80]$} \\
\hline & miR-106b & Hepatocellular carcinoma & {$[76,80]$} \\
\hline & miR-106a & Hepatocellular carcinoma & {$[75]$} \\
\hline & miR-519a-3p & Breast cancer & [81] \\
\hline & $\operatorname{miR}-125 b^{a}$ & Multiple myeloma & {$[82]$} \\
\hline & miR-373 & Hepatocellular carcinoma & {$[75]$} \\
\hline & miR-302c & Multiple cancers & {$[83]$} \\
\hline & miR-520c & Multiple cancers & {$[83]$} \\
\hline & $\operatorname{miR}-153^{b}$ & Pancreatic cancer & {$[84]$} \\
\hline \multirow[t]{13}{*}{ MICB } & \multirow[t]{2}{*}{ miR-20a } & Breast cancer & {$[77]$} \\
\hline & & Hepatocellular carcinoma & {$[75]$} \\
\hline & miR-373 & Hepatocellular carcinoma & {$[75]$} \\
\hline & miR-29a/b/c & Hepatocellular carcinoma & {$[75]$} \\
\hline & miR-15b & Hepatocellular carcinoma & {$[75]$} \\
\hline & miR-195 & Hepatocellular carcinoma & {$[75]$} \\
\hline & miR-16 & Hepatocellular carcinoma & {$[75]$} \\
\hline & miR-424 & Hepatocellular carcinoma & {$[75]$} \\
\hline & miR-106a & Hepatocellular carcinoma & {$[75]$} \\
\hline & miR-107 & Hepatocellular carcinoma & {$[75]$} \\
\hline & $\operatorname{miR}-17$ & Hepatocellular carcinoma & {$[75]$} \\
\hline & miR-302c & Multiple cancers & {$[83]$} \\
\hline & miR-520c & Multiple cancers & {$[83]$} \\
\hline \multirow[t]{4}{*}{ ULBP } & miR-20a & Breast cancer & {$[77]$} \\
\hline & miR-519a-3p & Breast cancer & [81] \\
\hline & miR-302c & Multiple cancers & [83] \\
\hline & miR-520c & Multiple cancers & [83] \\
\hline
\end{tabular}

MICA/B MHC-I chain-related molecules A/B (MICA/B), ULBP

UL16-binding protein

${ }^{a}$ miR-125b upregulates MICA via targeting the transcriptional suppressor of MICA

${ }^{b}$ miR-153 promotes the formation of SMICA by targeting HIF1A pathway

Previous studies demonstrated that overexpressed miR-20a in colorectal cancer cells, breast cancer cells, and ovarian cancer cells decreases MICA level and sensitivity to immune effector cells [74, 77-79]. Besides, it was found that miR-519a-3p undermined the tumorkilling effect of NKs by decreasing MICA and ULBP2 on breast cancer cells [81]. In breast cancer patients, high miR-519a-3p expression could be deemed as a predictive biomarker for poor prognosis [81]. In addition, Abruzzese et al. noticed that bromodomain and extra-terminal 
(BET) inhibitor could remarkably increase MICA expression on multiple myeloma cells [82]. This BETiinduced MICA elevation was mediated by miR-125b, which targeted the transcription suppressor of MICA (IRF4) [82]. Moreover, Kishikawa et al. found that miR93 and miR-106b targeted the 3'-UTR of MICA mRNA [80]. Genes coding miR-93 and miR-106b are both located in human chromosome 7q22.1 (termed miR25-93106b cluster) [80]. Silencing miR25-93-106b cluster significantly increased MICA expression and decreased the susceptibility of hepatocellular carcinoma cells to NKs [80]. Similarly to the observations of Kishikawa et al., Wu et al. noticed that a panel of miRNAs downregulated MHC-I chain-related molecules A/B (MICA/B) in hepatocellular carcinoma cells including miR-373, miR-29b, miR-15b, miR-195, miR-16, miR-424, miR-29c, miR106a, miR-107, miR-20a, miR-29a, as well as miR-17 [75]. Notably, 1, 25-(OH)2-D3 treatment could promote cancer immune surveillance by counteracting miR-302c/ miR-520c-induced downregulation of $\mathrm{MICA} / \mathrm{B}$ and ULBP2 downregulation [83].

On the contrary to MICA expressed on cancer cells (also known as membrane MICA), soluble MICA (sMICA) is an unfavorable factor for anti-cancer immunity [84]. In pancreatic cancer cells, hypoxiaassociated pathways conspicuously downregulated membrane MICA while simultaneously increased sMICA expression [84]. This hypoxia-induced sMICA upregulation was attributed to the dysregulated balance between circ_0000977 and miR-153 [84].

\section{Immune checkpoint ligand-associated miRNAs}

As a hallmark of cancer, upregulated immune checkpoint signal is determined by multiple factors, including previously existing inflammation and some oncogenic signaling pathways [85]. Increased immune checkpoint ligands especially PD-L1 is closely related with cancerassociated miRNA expression pattern. To be more specific, previous studies have indicated that the loss of miR-3609, miR-195-5p, miR-148a-3p, miR-873, miRNA497-5p, miR-191-5p, miR-34a, and miR-138 closely correlated with the increased PD-L1 expression on numerous cancer cells [86-94]. In addition, Dong et al. found that decreased miR-140, miR-142, miR-340, and miR383 enormously elevated PD-L1 expression on cervical cancer cells [95]. The results of a respective study demonstrated that in malignant pleural mesothelioma samples, the abundance of PD-L1 was negatively correlated with the levels of multiple cancer suppressive miRNAs including miR-15b, miR-16, miR-193a-3p, miR-195, and miR-200c [96]. Further investigation in cancer cell lines identified that miR-15b, miR-16, and miR-193a-3p could target PD-L1 mRNA [96]. Notably, some other long noncoding RNAs involved in the reduction of these PDL1-targeting miRNAs [87, 94].

Contrarily, miR-18a promotes PD-L1 expression by targeting PTEN, WNK2, and SOX6 [95]. Then, PI3KAKT, MEK-ERK, and Wnt/ $\beta$-catenin pathways are activated and the transcription activity of PD-L1 is upregulated [95]. Similarly, Tang et al. observed miR-3127-5p induced PD-L1 expression by promoting STAT3 phosphorylation in NSCLC cells [97]. The miRNAs associated with PD-L1 expression on cancer cells were summarized in Table 3.

\section{The miRNAs and tumor-mediated immune cell death}

Fas-FasL pathway has a great impact on immune tolerance in the tumor microenvironment [113]. Increased FasL on cancer cells counterattacks immune cells, induces immune cell death, and eventually promotes cancer immune privilege [114]. In $\mathrm{T}$ cell large granular lymphocyte leukemia, it was found that STAT3-induced miR-146b loss led to increased FasL expression and potential neutropenia [115]. Besides, the miR-768-3p mimic treatment in NSCLC cell immensely increased FasL level but decreased Fas expression on cancer cells [116]. Moreover, Wu et al. verified that miR-21 could target FasL in breast cancer cells. In the co-culture experiment, ectopically expressed miR-21 in MCF7 cells could remarkably reduce the apoptosis rate of Jurkat $\mathrm{T}$ cells [117]. Actually, FasL has been accepted as the posttranscriptional regulatory target of miR-21 in numerous cancer cell types including esophageal carcinoma and pancreatic cancer [118-120]. Notably, in spite of inhibiting immune evasion, highly expressed miR-21 was connected with cancer development, treatment resistance, and poor prognosis $[118,119]$.

\section{Cancer cell metabolite-related miRNAs}

Some cell metabolites such as tryptophan are essential to maintain the functions of TILs. IDO1 is a rate-limiting enzyme for tryptophan metabolism, which could convert tryptophan to kynurenine and 3-hydroxyanthranilic acid [121]. Increased IDO1 expression and decreased tryptophan lead to dysfunctional effector $\mathrm{T}$ cells and cancer immune evasion [122]. It was reported that downregulated miR-218 protected cervical cancer cells from immune attack via elevating IDO1 level [123]. Besides, Lou et al. found that miR-448 acted as a tumor suppressive factor by targeting downstream IDO1 in colon cancer cells. The results of in vitro study showed that the ectopic expression of miR-448 was beneficial to giving full play to the functions of TILs [124]. Moreover, Huang et al. reported that miR-153 level was a core factor determining the efficacy of chimeric antigen receptor (CAR) T cells treatment in colon cancer models. In colon cancer, miR-153 directly 
Table 3 The miRNAs regulating PD-L1 expression on cancer cells

\begin{tabular}{|c|c|c|c|}
\hline miRNAs & Effects of miRNA on PD-L1 expression & Cancer cell types & Ref. \\
\hline \multirow[t]{4}{*}{ miR-195-5p } & Downregulating & Pancreatic cancer & {$[87]$} \\
\hline & Downregulating & Colon adenocarcinoma & [91] \\
\hline & Downregulating & Prostate cancer & {$[98]$} \\
\hline & Downregulating & DLBCL & [99] \\
\hline miR-3609 & Downregulating & Breast cancer & {$[86]$} \\
\hline miR-148a-3p & Downregulating & Colorectal cancer & {$[88]$} \\
\hline miR-873 & Downregulating & Breast cancer & {$[89]$} \\
\hline miR-146a & Upregulating & Melanoma & {$[100]$} \\
\hline miR-497-5p & Downregulating & Clear cell renal cell carcinoma & {$[90]$} \\
\hline \multirow[t]{2}{*}{ miR-16 } & Downregulating & Prostate cancer & [98] \\
\hline & Downregulating & MPM & [96] \\
\hline \multirow[t]{3}{*}{ miR-34a } & Downregulating & B cell lymphomas & [92] \\
\hline & Downregulating & Glioma & [93] \\
\hline & Downregulating & AML & {$[101,102]$} \\
\hline \multirow[t]{2}{*}{ miR-140 } & Downregulating & Cervical cancer & {$[95]$} \\
\hline & Downregulating & NSCLC & [103] \\
\hline \multirow[t]{3}{*}{ miR-142 } & Downregulating & Cervical cancer & {$[95]$} \\
\hline & Downregulating & NSCLC & [104] \\
\hline & Downregulating & Pancreatic cancer & [105] \\
\hline $\operatorname{miR}-340$ & Downregulating & Cervical cancer & {$[95]$} \\
\hline miR-383 & Downregulating & Cervical cancer & {$[95]$} \\
\hline miR-18a & Upregulating & Cervical cancer & [95] \\
\hline miR-3127-5p & Upregulating & NSCLC & {$[97]$} \\
\hline \multirow[t]{3}{*}{ miR-200 family } & Downregulating & Lung cancer & [106] \\
\hline & Downregulating & Hepatocellular carcinoma & [107] \\
\hline & Downregulating & AML & [101] \\
\hline miR-375 & Downregulating & HNSCC & [108] \\
\hline \multirow[t]{2}{*}{$\operatorname{miR}-138$} & Downregulating & Colorectal cancer & {$[94]$} \\
\hline & Downregulating & Colorectal cancer & [109] \\
\hline miR-15a & Downregulating & MPM & [96] \\
\hline miR-193a-3p & Downregulating & MPM & [96] \\
\hline miR-93 & Downregulating & Pancreatic cancer & [110] \\
\hline miR-106b & Downregulating & Pancreatic cancer & [110] \\
\hline miR-17-5p & Downregulating & Melanoma & [111] \\
\hline miR-197 & Downregulating & NSCLC & [112] \\
\hline
\end{tabular}

NSCLC non-small cell lung cancer, HNSCC head and neck squamous cell carcinoma, DLBCL diffuse large B cell lymphoma, MPM malignant pleural mesothelioma, $A M L$ acute myeloid leukemia

targeted IDO1, enhancing cytotoxic activity of CAR T cells and inhibiting tumor growth [46].

\section{Cancer cell-derived miRNAs regulating immune evasion via exosomes or vehicles}

Cancer-derived miRNAs not only modulate the expression profile within cancer cells but also exhibit extracellular bioactivities by exosomes or microvesicles (Table 4)
[24]. Cancer-derived miRNAs could be packed into exosomes or microvesicles, which are transferred to numerous TILs and shape an immunosuppressive microenvironment (Fig. 3) [141].

Cancer-derived exosomal miRNAs and effector cells

Zhou et al. reported that the apoptosis ratio of $\mathrm{T}$ cells increased after treated with B16 cell-derived 
Table 4 Cancer cells-derived miRNAs regulating immune evasion via exosomes or vehicles

\begin{tabular}{|c|c|c|c|c|}
\hline $\begin{array}{l}\text { Immune cells regulated by cancer } \\
\text { cells-derived exosomal miRNAs }\end{array}$ & miRNAs & Cancer cell types & $\begin{array}{l}\text { Effects on anti-cancer } \\
\text { immune response }\end{array}$ & Ref. \\
\hline \multirow[t]{6}{*}{ Effector $T$ cells } & miR-690 & Melanoma & Immunosuppressive & [125] \\
\hline & miR-24-3p & NPC & Immunosuppressive & [126] \\
\hline & miR-891a & NPC & Immunosuppressive & [126] \\
\hline & miR-106a-5p & NPC & Immunosuppressive & [126] \\
\hline & miR-20a-5p & NPC & Immunosuppressive & [126] \\
\hline & miR-1908 & NPC & Immunosuppressive & [126] \\
\hline \multirow[t]{8}{*}{ TAMs } & miR-222-3p & EOC & Immunosuppressive & [127] \\
\hline & miR-940 & EOC & Immunosuppressive & [128] \\
\hline & miR-21-3p & EOC & Immunosuppressive & [129] \\
\hline & miR-125b-5p & EOC & Immunosuppressive & [129] \\
\hline & miR-181d-5p & EOC & Immunosuppressive & [129] \\
\hline & miR-21 & Head and neck cancer & Immunosuppressive & [130] \\
\hline & miR-1246 & Colon cancer & Immunosuppressive & [131] \\
\hline & miR-16 & Breast cancer & Immunostimulatory & [132] \\
\hline \multirow[t]{7}{*}{ MDSCs } & miR-107 & Gastric cancer & Immunosuppressive & [133] \\
\hline & miR-21 & oscc & Immunosuppressive & [134] \\
\hline & miR-21 & Glioma & Immunosuppressive & [135] \\
\hline & miR-10a & Glioma & Immunosuppressive & [135] \\
\hline & miR-29a & Glioma & Immunosuppressive & [136] \\
\hline & miR-92a & Glioma & Immunosuppressive & [136] \\
\hline & miR-155 & CLL & Immunosuppressive & [137] \\
\hline \multirow[t]{3}{*}{ CAFs } & miR-27a & Gastric cancer & Immunosuppressive & [138] \\
\hline & miR-1247-3p & $\mathrm{HCC}$ & Immunosuppressive & [139] \\
\hline & miR-21 & $\mathrm{HCC}$ & Immunosuppressive & [140] \\
\hline
\end{tabular}

NPC nasopharyngeal carcinoma, TAM tumor-associated macrophage, EOC epithelial ovarian cancer, MDSC myeloid-derived suppressor cell, OSCC oral squamous cell carcinoma, CLL chronic lymphocytic leukemia, CAF cancer-associated fibroblast, HCC hepatocellular carcinoma

exosomes [125]. When the release of exosome was inhibited, the abundance of TILs elevated and tumor growth was retarded [125]. Further investigation found that the cancer-derived exosomes extraordinarily increased pro-apoptotic proteins (e.g., caspase-3/7/ 9) and decreased anti-apoptotic proteins (e.g., BCL-2/ $\mathrm{xL}$ and MCL-1) in $\mathrm{CD}^{+} \mathrm{T}$ cells [125]. In silico analysis indicated that a group of cancer-derived exosomal miRNAs such as miR-690 might contribute to this mitochondrial apoptosis of $\mathrm{T}$ cells [125]. Besides, Ye et al. found that TW03 (nasopharyngeal carcinoma cell)-derived exosomes impaired the proliferation and differentiation of $\mathrm{T}$ cells [126]. Meanwhile, TW03derived exosomes remarkably downregulated the generation of cytokines including IL-2, IFN- $\gamma$, and IL-17 [126]. It was proposed that a set of commonly overexpressed miRNAs (miR-24-3p, miR-891a, miR-106a$5 \mathrm{p}, \mathrm{miR}-20 \mathrm{a}-5 \mathrm{p}$, and miR-1908) were responsible for the undermined functions of $\mathrm{T}$ cells [126].

\section{Cancer-derived exosomal miRNAs and TAMs}

Macrophages are usually categorized into proinflammatory (M1) populations and anti-inflammatory (M2) populations [142]. Abundant M2-like TAMs in the tumor microenvironment promote carcinogenesis by inducing angiogenesis, suppressing anti-cancer immune response, and antagonizing cancer cell apoptosis [143]. Epithelial ovarian cancer cells induced the polarization of TMAs toward M2-like phenotype via secreting exosomal miR-222-3p and miR-940 [127, 128]. Besides, under hypoxic condition, epithelial ovarian cancer cell-secreted exosomes contained miRNAs such as miR-21-3p, miR125b-5p, and miR-181d-5p, which enhanced the polarization of M2-like TAMs and promoted cancer growth [129]. Moreover, Hsieh et al. found that some snail-overexpressed cancer cells generated miR-21containing exosomes during epithelial-mesenchymal transition (EMT) [130]. These exosomes were engulfed by $\mathrm{CD} 14^{+}$monocytes, inducing the polarization toward 


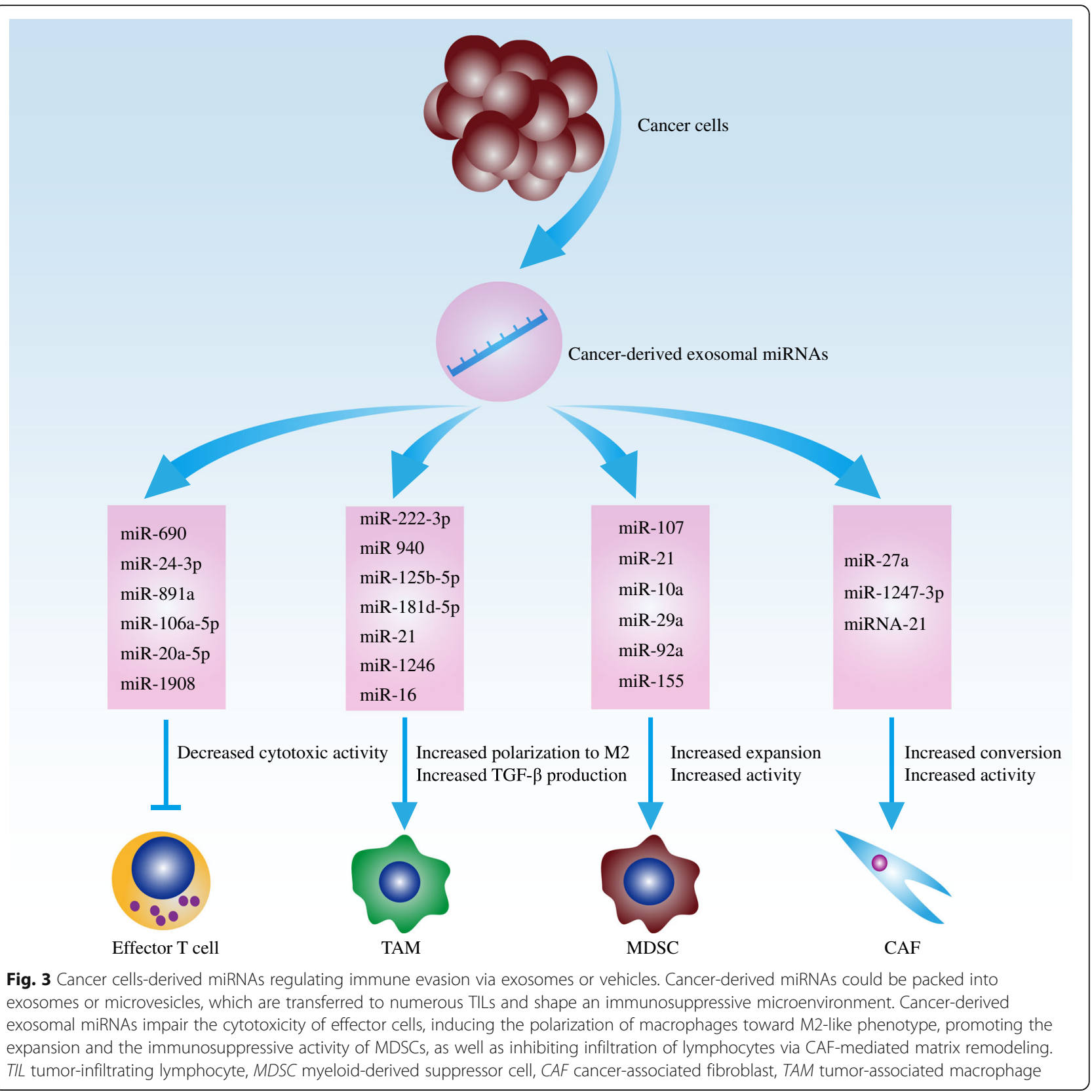

M2-like phenotype and suppressing the expression of M1 phenotype-associated markers [130]. Similarly, Cooks et al. observed that cancer cells harboring TP53 mutation could reprogram neighboring TAMs into pro-tumor state via secreting miR-1246-enriched exosomes [131]. After uptake of exosomal miR-1246, TAMs exhibited higher immunosuppression activity with upregulated TGF- $\beta$ production [131]. Notably, it was reported that epigallocatechin gallate increased the level of miR-16 in breast cancer cells (4T1 cells) which could be further transferred into TAMs by exosomes and decreased the abundance of M2-like TAMs [132].

\section{Cancer-derived exosomal miRNAs and MDSCs}

Accumulating evidence has indicated that cancerderived exosomal miRNAs are capable of regulating the abundance and function of MDSCs [144]. Ren et al. reported that gastric cancer cells enhanced the expansion and activity of MDSCs by delivering miRNA-107enriched exosomes [133]. Similarly, in the condition of hypoxia, glioma secreted exosomal miR-29a and miR92a which enhanced the proliferation and function of MDSCs via targeting Hbp1 as well as Prkar1a [136]. Besides, this hypoxia-induced glioma could generate exosomal miR-10a and miR-21 to propel the expansion and activation of MDSCs [135]. Additionally, it was found 
that oral squamous cell carcinoma-derived exosomal miR-21 activated the downstream PTEN-PD-L1 pathway in MDSCs, which further enhanced the immune tolerance in the tumor microenvironment [134]. However, this exosomal-mediated MDSCs induction could be interfered by additional vitamin D treatment. Analogously, Bruns et al. found that chronic lymphocytic leukemiaderived miR-155 induced the formation of MDSCs but this process was hampered by vitamin $\mathrm{D}$ treatment [137].

\section{Cancer cells-derived exosomal miRNAs and cancer- associated fibroblasts}

As the most abundant cells of cancer stroma, cancerassociated fibroblasts (CAFs) secret multiple cytokines and extracellular matrix components such as collagens and fibronectins, which generate a physical barrier separating lymphocytes from tumor and inhibiting the infiltration of effector cells [145]. Hyperactive CAF is an unfavorable prognostic factor for patients receiving immunotherapy [44]. Cancer-derived exosomal miRNA is a vital factor accounting for increased CAFs in the tumor microenvironment. Gastric cancer-derived exosomal miR-27a promoted the transformation from normal fibroblasts toward CAFs [138]. In addition, Fang et al. found that metastatic hepatocellular carcinoma cells produced exosomal miR-1247-3p which could target B4GALT3 and activate $\beta 1$-integrin-NF- $\mathrm{B}$ s signaling pathway in CAFs [139]. Besides, Zhou et al. observed that hepatocellular carcinoma enhanced the activity of CAFs by exosomal miRNA-21-PTEN-PDK1/AKT pathway [140].

\section{The effect of miRNAs on immunotherapy}

Due to the substantial influence of some cancer cellderived miRNAs on anti-cancer immune response, it is promising to develop miRNA-based diagnostic tools and therapeutic applications. In NSCLC mouse models, it was found that miR-34a suppressed PD-L1 expression by binding to its 3'UTR region. Therapeutic injection of liposomal nanoparticles containing miR-34a mimics increased the abundance of TILs and decreased the ratio of PD- $1^{+} \mathrm{CD}^{+} \mathrm{T}$ cells [146]. Theoretically, this miRNA-based treatment is synergistic with following immunotherapies.

In addition, some miRNAs are determinates of efficacy of immune checkpoint inhibitors. Zhang et al. found that circFGFR1 acted as the miRNA sponge of miR-381-3p and induced the therapeutic resistance to PD-1 blockade [147]. Besides, Nakahara et al. reported that the high levels of miR-16-5p, miR-17-5p, and miR-20a-5p were the indicators of responders of melanoma patients receiving anti-PD-1 therapy [148]. Moreover, Zheng et al. observed that miR-155 induced the apoptosis of $\mathrm{T}$ cells by Fas-FasL pathway and upregulated the expression of
PD-L1 on lymphoma cells. The results of in vivo study showed that the miR-155 overexpressed lymphoma cells were highly sensitive to PD-L1 blockade treatment [149]. More and more evidence suggested that some specific miRNA expression patterns could predict immunotherapy resistance. It was documented that a panel of miRNAs including miR-99b, miR-100, miR-125a/b, and $\mathrm{miR}-146 \mathrm{a} / \mathrm{b}$ highly related with treatment resistance to immune checkpoint blockade in melanoma patients. These miRNAs could induce the conversion of myeloid cells to MDSC and herald poor immunotherapy outcomes [150].

Apart from immune checkpoint inhibitors, it has been verified that some miRNAs affect the efficacy of other immunotherapies such as CAR $\mathrm{T}$ cells. In xenograft tumor of human colon cancer, miR-153 inhibited the expression of IDO and enhanced the effect of CAR T cells targeting epidermal growth factor receptor [46]. In addition, Zhang et al. found that miR-143 promoted the differentiation of central memory $\mathrm{T}$ cells and increased the secretion of cytokines. Further investigation indicated that miR-143 overexpression boosted the specific killing activity of HER2-CAR T cells against TE-7 cells by inhibiting glucose uptake and glycolysis [151].

\section{Perspective and conclusion}

Alteration in miRNA expression profile plays an indispensable role in carcinogenesis. Upregulated oncomiRNAs and downregulated tumor-suppressed miRNAs render cancer cells with enhanced viability and invasiveness. We noticed that more and more clinical studies try to predict the patients' prognosis or treatment efficiency by analyzing miRNA expression profile. It was more refreshing that multiple onco-miRNA-targeted agents had been designed such as miR-RX34 liposomal. Besides, Liang et al. designed an engineered exosome which could deliver chemotherapeutic drugs 5-Fluorouracil and miR-21 inhibitor oligonucleotide to $\mathrm{Her}^{+}$colon cancer cells. This co-delivering by exosomes showed potent anti-cancer effect in mouse models and reversed the chemotherapy resistance to 5-Fluorouracil [152]. The efficacy and safety of these novel targeted therapies were undergoing evaluation. The concept of miRNA has a profound implication in understanding numerous cancer malignant biological behaviors.

Apart from participating carcinogenesis, some specific miRNA expression pattern could predict cancer immune evasion. We proposed that it would be feasible to utilize miRNA expression profiles and other parameters to construct a comprehensive framework for evaluating patients' immune state. This evaluation is meaningful to determine further treatment options. Besides, normalizing these immunosuppressive miRNA expression patterns might have a synergistic effect with simultaneous immunotherapy. 


\section{Abbreviations}

3'-UTR: 3'-untranslated region; APC: Antigen presentation cells; Arg1: Arginase-1; APM: Antigen processing machinery; CAF: Cancerassociated fibroblast; CAR: Chimeric antigen receptor; CTL: Cytotoxic T lymphocyte; GPER: G-protein-coupled estrogen receptor-1; HLA: Human leukocyte antigen; IDO: Indoleamine 2, 3-dioxygenase; IFN: Interferon; IL10: Interleukin-10; iNOS: Inducible nitric oxide synthase; LMP: Proteasome subunits latent membrane protein; MDSC: Myeloid-derived suppressor cell; MHC-I: Major histocompatibility complex class I; MICA/B: MHC-I chain-related molecules A/B; NSCLC: Non-small cell lung cancer; Ship1: Sh2 domain containing inositol phosphatase-1; SOCS-1: Suppressor of cytokine signaling 1; TAM: Tumor-associated macrophage; TGF- $\beta$ : Transforming growth factor- $\beta$; TIL: Tumor-infiltrating lymphocyte; TIM-3: T cell immunoglobulin and mucin domain-containing protein 3; ULBP: UL16-binding protein; VISTA: V-domain Ig suppressor of T cell activation; TAA: Tumor-associated antigen; TAP: Transporter associated with antigen processing; TIGIT: T cell immunoreceptor with Ig and ITIM domains

\section{Acknowledgments}

We thank Drs. Shuang Qin and Tianye Li of Tongji Hospital for helpful discussion and language editing assistance.

\section{Authors' contributions}

All authors contributed to drafting and revising the article, gave final approval of the version to be published, and agree to be accountable for all aspects of the work.

\section{Funding}

This work was supported by the National Natural Science Foundation of China (No. 81874120, 81572608), Wuhan Science and Technology Bureau (No. 2017060201010170), Henan science and technology open cooperation project (No. 162106000021).

\section{Availability of data and materials}

Data sharing not applicable to this article as no datasets were generated or analyzed during the current study.

\section{Ethics approval and consent to participate}

Not applicable.

\section{Consent for publication}

Not applicable.

\section{Competing interests}

The authors declare that they have no competing interests.

Received: 30 November 2019 Accepted: 14 February 2020

Published online: 28 March 2020

\section{References}

1. Chen DS, Mellman I. Oncology meets immunology: the cancer-immunity cycle. Immunity. 2013;39:1-10.

2. Yi M, Qin S, Zhao W, Yu S, Chu Q, Wu K. The role of neoantigen in immune checkpoint blockade therapy. Exp Hematol Oncol. 2018;7:28.

3. Metelli A, Salem M, Wallace CH, Wu BX, Li A, Li X, et al. Immunoregulatory functions and the therapeutic implications of GARP-TGF-beta in inflammation and cancer. J Hematol Oncol. 2018;11:24

4. Kim JM, Chen DS. Immune escape to PD-L1/PD-1 blockade: seven steps to success (or failure). Ann Oncol. 2016;27:1492-504.

5. Vinay DS, Ryan EP, Pawelec G, Talib WH, Stagg J, Elkord E, et al. Immune evasion in cancer: Mechanistic basis and therapeutic strategies. Semin Cancer Biol. 2015;35(Suppl):S185-98

6. Alissafi T, Hatzioannou A, Legaki Al, Varveri A, Verginis P. Balancing cancer immunotherapy and immune-related adverse events: The emerging role of regulatory T cells. J Autoimmun. 2019;104:102310.

7. Marin-Acevedo JA, Soyano AE, Dholaria B, Knutson KL, Lou Y. Cance immunotherapy beyond immune checkpoint inhibitors. J Hematol Oncol. 2018;11:8.

8. Eggermont AMM, Blank CU, Mandala M, Long GV, Atkinson V, Dalle S, et al. Adjuvant Pembrolizumab versus Placebo in Resected Stage III Melanoma. N Engl J Med. 2018;378:1789-801.
9. Forde PM, Chaft JE, Smith KN, Anagnostou V, Cottrell TR, Hellmann MD, et al. Neoadjuvant PD-1 Blockade in Resectable Lung Cancer. N Engl J Med. 2018;378:1976-86

10. Wang $D$, Lin J, Yang $X$, Long J, Bai $Y$, Yang $X$, et al. Combination regimens with PD-1/PD-L1 immune checkpoint inhibitors for gastrointestinal malignancies. J Hematol Oncol. 2019;12:42.

11. Chen DS, Mellman I. Elements of cancer immunity and the cancer-immune set point. Nature. 2017;541:321-30.

12. Lan Y, Zhang D, Xu C, Hance KW, Marelli B, Qi J, et al. Enhanced preclinical antitumor activity of M7824, a bifunctional fusion protein simultaneously targeting PD-L1 and TGF-beta. Sci Transl Med. 2018. https://doi.org/10.1126/ scitranslmed.aan5488.

13. Wu CJ, Lu LF. MicroRNA in Immune regulation. Curr Top Microbiol Immunol. 2017:410:249-67.

14. Marzagalli M, Ebelt ND, Manuel ER. Unraveling the crosstalk between melanoma and immune cells in the tumor microenvironment. Semin Cancer Biol. 2019;59:236-50.

15. Leichter AL, Sullivan MJ, Eccles MR, Chatterjee A. MicroRNA expression patterns and signalling pathways in the development and progression of childhood solid tumours. Mol Cancer. 2017;16:15.

16. Chen J, Zhou R, Liang Y, Fu X, Wang D, Wang C. Blockade of IncRNAASLNCS5088-enriched exosome generation in M2 macrophages by GW4869 dampens the effect of M2 macrophages on orchestrating fibroblast activation. FASEB J. 2019;33:12200-12.

17. Liu X, Luo M, Meng H, Zeng Q, Xu L, Hu B, et al. MiR-181a regulates CD4(+) T cell activation and differentiation by targeting $\mathrm{IL}-2$ in the pathogenesis of myasthenia gravis. Eur J Immunol. 2019. https://doi.org/10.1002/eji.201848007.

18. Goncalves-Alves E, Saferding V, Schliehe C, Benson R, Kurowska-Stolarska M, Brunner JS, et al. MicroRNA-155 Controls T Helper Cell Activation During Viral Infection. Front Immunol. 2019;10:1367.

19. Fleshner M, Crane CR. Exosomes, DAMPs and miRNA: features of stress physiology and immune homeostasis. Trends Immunol. 2017;38:768-76.

20. Chang YY, Kuo WH, Hung JH, Lee CY, Lee YH, Chang YC, et al. Deregulated microRNAs in triple-negative breast cancer revealed by deep sequencing. Mol Cancer. 2015;14:36.

21. Wang WT, Han C, Sun YM, Chen TQ, Chen YQ. Noncoding RNAs in cancer therapy resistance and targeted drug development. J Hematol Oncol. 2019;12:55.

22. Ni SJ, Zhao LQ, Wang XF, Wu ZH, Hua RX, Wan $C H$, et al. CBX7 regulates stem cell-like properties of gastric cancer cells via p16 and AKT-NFkappaBmiR-21 pathways. J Hematol Oncol. 2018;11:17.

23. Sun Z, Shi K, Yang S, Liu J, Zhou Q, Wang G, et al. Effect of exosomal miRNA on cancer biology and clinical applications. Mol Cancer. 2018;17:147.

24. Eichmuller SB, Osen W, Mandelboim O, Seliger B. Immune modulatory microRNAs Involved in tumor attack and tumor immune escape. J Natl Cancer Inst. 2017. https://doi.org/10.1093/jnci/djx034.

25. Arrieta VA, Cacho-Diaz B, Zhao J, Rabadan R, Chen L, Sonabend AM. The possibility of cancer immune editing in gliomas. A critical review. Oncoimmunology. 2018;7:e1445458.

26. Schreiber RD, Old $\amalg$, Smyth MJ. Cancer immunoediting: integrating immunity's roles in cancer suppression and promotion. Science. 2011;331:1565-70.

27. Dunn GP, Old $L$, Schreiber RD. The immunobiology of cancer immunosurveillance and immunoediting. Immunity. 2004;21:137-48.

28. Saleh $R$, Elkord E. Acquired resistance to cancer immunotherapy: Role of tumor-mediated immunosuppression. Semin Cancer Biol. 2019. https://doi. org/10.1016/j.semcancer.2019.07.017.

29. Taylor A, Verhagen J, Blaser K, Akdis M, Akdis CA. Mechanisms of immune suppression by interleukin-10 and transforming growth factor-beta: the role of T regulatory cells. Immunology. 2006;117:433-42.

30. Liu F, Liu Y, Chen Z. Tim-3 expression and its role in hepatocellular carcinoma. J Hematol Oncol. 2018;11:126.

31. Joller N, Lozano E, Burkett PR, Patel B, Xiao S, Zhu C, et al. Treg cells expressing the coinhibitory molecule TIGIT selectively inhibit proinflammatory Th1 and Th17 cell responses. Immunity. 2014;40:569-81.

32. Wang L, Rubinstein $R$, Lines IL, Wasiuk A, Ahonen C, Guo Y, et al. VISTA, a novel mouse Ig superfamily ligand that negatively regulates $T$ cell responses. J Exp Med. 2011;208:577-92.

33. Marin-Acevedo JA, Dholaria B, Soyano AE, Knutson KL, Chumsri S, Lou Y. Next generation of immune checkpoint therapy in cancer: new developments and challenges. J Hematol Oncol. 2018;11:39.

34. Saleh $\mathrm{R}$, Elkord E. Treg-mediated acquired resistance to immune checkpoint inhibitors. Cancer Lett. 2019;457:168-79. 
35. Achour A, Simon Q, Mohr A, Seite JF, Youinou P, Bendaoud B, et al. Human regulatory $B$ cells control the TFH cell response. J Allergy Clin Immunol. 2017; 140:215-22

36. Khan AR, Hams E, Floudas A, Sparwasser T, Weaver CT, Fallon PG. PD-L1hi B cells are critical regulators of humoral immunity. Nat Commun. 2015;6:5997.

37. Fehres $C M$, van Uden NO, Yeremenko NG, Fernandez L, Franco Salinas G, van Duivenvoorde LM, et al. APRIL Induces a Novel Subset of IgA(+) Regulatory B Cells That Suppress Inflammation via Expression of IL-10 and PD-L1. Front Immunol. 2019;10:1368.

38. Gabrilovich DI, Nagaraj S. Myeloid-derived suppressor cells as regulators of the immune system. Nat Rev Immunol. 2009;9:162-74.

39. Liu Y, Wei G, Cheng WA, Dong Z, Sun H, Lee W, et al. Targeting myeloidderived suppressor cells for cancer immunotherapy. Cancer Immunol Immunother. 2018;67:1181-95.

40. Nagaraj S, Gupta K, Pisarev V, Kinarsky L, Sherman S, Kang L, et al. Altered recognition of antigen is a mechanism of CD8+ T cell tolerance in cancer. Nat Med. 2007;13:828-35.

41. Lin $Y, X u$ J, Lan H. Tumor-associated macrophages in tumor metastasis: biological roles and clinical therapeutic applications. J Hematol Oncol. 2019;12:76.

42. Restifo NP, Esquivel F, Kawakami Y, Yewdell JW, Mule JJ, Rosenberg SA, et al. Identification of human cancers deficient in antigen processing. J Exp Med. 1993;177:265-72.

43. Travis MA, Sheppard D. TGF-beta activation and function in immunity. Annu Rev Immunol. 2014;32:51-82.

44. Mariathasan S, Turley SJ, Nickles D, Castiglioni A, Yuen K, Wang Y, et al. TGFbeta attenuates tumour response to PD-L1 blockade by contributing to exclusion of T cells. Nature. 2018:554:544-8.

45. Yi M, Jiao D, Qin S, Chu Q, Wu K, Li A. Synergistic effect of immune checkpoint blockade and anti-angiogenesis in cancer treatment. Mol Cancer. 2019;18:60

46. Huang Q, Xia J, Wang L, Wang X, Ma X, Deng Q, et al. miR-153 suppresses IDO1 expression and enhances CAR T cell immunotherapy. J Hematol Oncol. 2018;11:58.

47. Mondanelli G, Ugel S, Grohmann U, Bronte V. The immune regulation in cancer by the amino acid metabolizing enzymes ARG and IDO. Curr Opin Pharmacol. 2017;35:30-9.

48. Bradford JW, Baldwin AS. IKK/nuclear factor-kappaB and oncogenesis: roles in tumor-initiating cells and in the tumor microenvironment. Adv Cancer Res. 2014;121:125-45.

49. Omar HA, El-Serafi AT, Hersi F, Arafa EA, Zaher DM, Madkour M, et al. Immunomodulatory MicroRNAs in cancer: targeting immune checkpoints and the tumor microenvironment. FEBS J. 2019;286:3540-57.

50. Seliger B. Immune modulatory microRNAs as a novel mechanism to revert immune escape of tumors. Cytokine Growth Factor Rev. 2017;36:49-56.

51. Whiteside TL. The effect of tumor-derived exosomes on immune regulation and cancer immunotherapy. Future Oncol. 2017;13:2583-92.

52. Moore C, Kosgodage $U$, Lange S, Inal JM. The emerging role of exosome and microvesicle- (EMV-) based cancer therapeutics and immunotherapy. Int J Cancer. 2017;141:428-36.

53. Gao F, Zhao ZL, Zhao WT, Fan QR, Wang SC, Li J, et al. miR-9 modulates the expression of interferon-regulated genes and MHC class I molecules in human nasopharyngeal carcinoma cells. Biochem Biophys Res Commun. 2013;431:610-6.

54. Mari L, Hoefnagel SJM, Zito D, van de Meent M, van Endert $P$, Calpe $S$, et al, microRNA 125a Regulates MHC-I Expression on Esophageal Adenocarcinoma Cells, Associated With Suppression of Antitumor Immune Response and Poor Outcomes of Patients. Gastroenterology. 2018;155:784-98.

55. Yin P, Peng R, Peng H, Yao L, Sun $Y$, Wen L, et al. MiR-451 suppresses cell proliferation and metastasis in A549 lung cancer cells. Mol Biotechnol. 2015;57:1-11.

56. Colangelo T, Polcaro G, Ziccardi P, Pucci B, Muccillo L, Galgani M, et al. Proteomic screening identifies calreticulin as a miR-27a direct target repressing $\mathrm{MHC}$ class I cell surface exposure in colorectal cancer. Cell Death Dis. 2016;7:e2120.

57. Park S, Eom K, Kim J, Bang H, Wang HY, Ahn S, et al. MiR-9, miR-21, and miR-155 as potential biomarkers for HPV positive and negative cervical cancer. BMC Cancer. 2017;17:658

58. Han L, Wang W, Ding W, Zhang L. MiR-9 is involved in TGF-beta1-induced lung cancer cell invasion and adhesion by targeting SOX7. J Cell Mol Med. 2017;21:2000-8.

59. Chen X, Yang F, Zhang T, Wang W, Xi W, Li Y, et al. MiR-9 promotes tumorigenesis and angiogenesis and is activated by MYC and OCT4 in human glioma. J Exp Clin Cancer Res. 2019;38:99.
60. Bartoszewski R, Brewer JW, Rab A, Crossman DK, Bartoszewska S, Kapoor N, et al. The unfolded protein response (UPR)-activated transcription factor Xbox-binding protein 1 (XBP1) induces microRNA-346 expression that targets the human antigen peptide transporter 1 (TAP1) mRNA and governs immune regulatory genes. J Biol Chem. 2011;286:41862-70.

61. Ferreira LMR, Meissner TB, Tilburgs T, Strominger JL. HLA-G: At the Interface of Maternal-Fetal Tolerance. Trends Immunol. 2017;38:272-86.

62. Carosella ED, Rouas-Freiss N, Tronik-Le Roux D, Moreau P, LeMaoult J. HLA$\mathrm{G}$ : an immune checkpoint molecule. Adv Immunol. 2015;127:33-144.

63. Paul P, Rouas-Freiss N, Khalil-Daher I, Moreau P, Riteau B, Le Gal FA, et al. HLA-G expression in melanoma: a way for tumor cells to escape from immunosurveillance. Proc Natl Acad Sci U S A. 1998;95:4510-5.

64. Yan WH. Human leukocyte antigen-G in cancer: are they clinically relevant? Cancer Lett. 2011;311:123-30.

65. Manaster I, Goldman-Wohl D, Greenfield C, Nachmani D, Tsukerman P, Hamani $Y$, et al. MiRNA-mediated control of HLA-G expression and function. PLoS One. 2012;7:e33395.

66. Jasinski-Bergner S, Stehle F, Gonschorek E, Kalich J, Schulz K, Huettelmaier S, et al. Identification of 14-3-3beta gene as a novel miR-152 target using a proteome-based approach. J Biol Chem. 2014;289:31121-35.

67. Zhu XM, Han T, Wang XH, Li YH, Yang HG, Luo YN, et al. Overexpression of miR-152 leads to reduced expression of human leukocyte antigen- $G$ and increased natural killer cell mediated cytolysis in JEG-3 cells. Am J Obstet Gynecol. 2010;202:592.e1-7.

68. Tao S, He H, Chen Q, Yue W. GPER mediated estradiol reduces miR-148a to promote HLA-G expression in breast cancer. Biochem Biophys Res Commun. 2014:451:74-8.

69. Wang X, Li B, Wang J, Lei J, Liu C, Ma Y, et al. Evidence that miR-133a causes recurrent spontaneous abortion by reducing HLA-G expression. Reprod BioMed Online. 2012;25:415-24.

70. Schmiedel D, Mandelboim O. NKG2D Ligands-critical targets for cancer immune escape and therapy. Front Immunol. 2018;9:2040.

71. Yadav D, Ngolab J, Lim RS, Krishnamurthy S, Bui JD. Cutting edge: downregulation of $\mathrm{MHC}$ class I-related chain A on tumor cells by IFN-gammainduced microRNA. J Immunol. 2009;182:39-43.

72. Stern-Ginossar N, Gur C, Biton M, Horwitz E, Elboim M, Stanietsky N, et al. Human microRNAs regulate stress-induced immune responses mediated by the receptor NKG2D. Nat Immunol. 2008:9:1065-73.

73. Zhang J, Basher F, Wu JD. NKG2D ligands in tumor immunity: two sides of a coin. Front Immunol. 2015;6:97.

74. Xie J, Liu M, Li Y, Nie Y, Mi Q, Zhao S. Ovarian tumor-associated microRNA20a decreases natural killer cell cytotoxicity by downregulating MICA/B expression. Cell Mol Immunol. 2014;11:495-502.

75. Wu J, Zhang XJ, Shi KQ, Chen YP, Ren YF, Song YJ, et al. Hepatitis B surface antigen inhibits MICA and MICB expression via induction of cellular miRNAs in hepatocellular carcinoma cells. Carcinogenesis. 2014;35:155-63.

76. Yang H, Lan P, Hou Z, Guan Y, Zhang J, Xu W, et al. Histone deacetylase inhibitor SAHA epigenetically regulates miR-17-92 cluster and MCM7 to upregulate MICA expression in hepatoma. Br J Cancer. 2015;112:112-21.

77. Shen J, Pan J, Du C, Si W, Yao M, Xu L, et al. Silencing NKG2D ligandtargeting miRNAs enhances natural killer cell-mediated cytotoxicity in breast cancer. Cell Death Dis. 2017;8:e2740.

78. Tang S, Fu H, Xu Q, Zhou Y. miR-20a regulates sensitivity of colorectal cancer cells to NK cells by targeting MICA. Biosci Rep. 2019. https://doi.org/ 10.1042/BSR20180695.

79. Shekari N, Javadian M, Ghaffari S, Baradaran B, Darabi M, Kazemi T. DHA Abolishes the Detrimental Effect of Docetaxel on Downregulation of the MICA via Decreasing the Expression Level of MicroRNA-20a in Gastric Cancer. J Gastrointest Cancer. 2019. https://doi.org/10.1007/s12029-01900280-3.

80. Kishikawa T, Otsuka M, Yoshikawa T, Ohno M, Takata A, Shibata C, et al. Regulation of the expression of the liver cancer susceptibility gene MICA by microRNAs. Sci Rep. 2013;3:2739.

81. Breunig C, Pahl J, Kublbeck M, Miller M, Antonelli D, Erdem N, et al. MicroRNA519a-3p mediates apoptosis resistance in breast cancer cells and their escape from recognition by natural killer cells. Cell Death Dis. 2017;8:e2973.

82. Abruzzese MP, Bilotta MT, Fionda C, Zingoni A, Soriani A, Vulpis E, et al. Inhibition of bromodomain and extra-terminal (BET) proteins increases NKG2D ligand MICA expression and sensitivity to NK cell-mediated cytotoxicity in multiple myeloma cells: role of cMYC-IRF4-miR-125b interplay. J Hematol Oncol. 2016;9:134. 
83. Min D, Lv XB, Wang X, Zhang B, Meng W, Yu F, et al. Downregulation of miR-302C and miR-520 by $1,25(\mathrm{OH}) 2 \mathrm{D} 3$ treatment enhances the susceptibility of tumour cells to natural killer cell-mediated cytotoxicity. Br J Cancer. 2013;109:723-30.

84. Ou ZL, Luo Z, Wei W, Liang S, Gao TL, Lu YB. Hypoxia-induced shedding of MICA and HIF1A-mediated immune escape of pancreatic cancer cells from NK cells: role of circ_0000977/miR-153 axis. RNA Biol. 2019:1-12.

85. Yi M, Jiao D, Xu H, Liu Q, Zhao W, Han X, et al. Biomarkers for predicting efficacy of PD-1/PD-L1 inhibitors. Mol Cancer. 2018;17:129.

86. Li D, Wang X, Yang M, Kan Q, Duan Z. miR3609 sensitizes breast cancer cells to adriamycin by blocking the programmed death-ligand 1 immune checkpoint. Exp Cell Res. 2019;380:20-8.

87. Zhou WY, Zhang MM, Liu C, Kang Y, Wang JO, Yang XH. Long noncoding RNA LINC00473 drives the progression of pancreatic cancer via upregulating programmed death-ligand 1 by sponging microRNA-195-5p. J Cell Physiol. 2019;234:23176-89.

88. Ashizawa M, Okayama H, Ishigame T, Thar Min AK, Saito K, Ujiie D, et al. miRNA148a-3p Regulates Immunosuppression in DNA Mismatch Repair- Deficient Colorectal Cancer by Targeting PD-L1. Mol Cancer Res. 2019;17:1403-13.

89. Gao L, Guo Q, Li X, Yang X, Ni H, Wang T, et al. MiR-873/PD-L1 axis regulates the stemness of breast cancer cells. EBioMedicine. 2019;41:395-407.

90. Qu F, Ye J, Pan X, Wang J, Gan S, Chu C, et al. MicroRNA-497-5p downregulation increases PD-L1 expression in clear cell renal cell carcinoma. J Drug Target. 2019;27:67-74.

91. Chen XY, Zhang J, Hou LD, Zhang R, Chen W, Fan HN, et al. Upregulation of PD-L1 predicts poor prognosis and is associated with miR-191-5p dysregulation in colon adenocarcinoma. Int J Immunopathol Pharmacol. 2018:32:2058738418790318.

92. Anastasiadou E, Stroopinsky D, Alimperti S, et al. Epstein-Barr virus-encoded EBNA2 alters immune checkpoint PD-L1 expression by downregulating miR34a in B-cell lymphomas. Leukemia. 2019;33:132-47.

93. Wang $Y$, Wang L. miR-34a attenuates glioma cells progression and chemoresistance via targeting PD-L1. Biotechnol Lett. 2017;39:1485-92.

94. Zhang XL, Xu LL, Wang F. Hsa_circ_0020397 regulates colorectal cancer cell viability, apoptosis and invasion by promoting the expression of the miR138 targets TERT and PD-L1. Cell Biol Int. 2017:41:1056-64.

95. Dong P, Xiong Y, Yu J, Chen L, Tao T, Yi S, et al. Control of PD-L1 expression by miR-140/142/340/383 and oncogenic activation of the OCT4-miR-18a pathway in cervical cancer. Oncogene. 2018;37:5257-68.

96. Kao SC, Cheng YY, Williams M, Kirschner MB, Madore J, Lum T, et al. Tumor Suppressor microRNAs Contribute to the Regulation of PD-L1 Expression in Malignant Pleural Mesothelioma. J Thorac Oncol. 2017;12:1421-33.

97. Tang D, Zhao D, Wu Y, Yao R, Zhou L, Lu L, et al. The miR-3127-5p/p-STAT3 axis up-regulates PD-L1 inducing chemoresistance in non-small-cell lung cancer. J Cell Mol Med. 2018. https://doi.org/10.1111/jcmm.13657.

98. Tao Z, Xu S, Ruan H, Wang T, Song W, Qian L, et al. MiR-195/-16 Family Enhances Radiotherapy via T Cell Activation in the Tumor Microenvironment by Blocking the PD-L1 Immune Checkpoint. Cell Physiol Biochem. 2018:48:801-14.

99. He B, Yan F, Wu C. Overexpressed miR-195 attenuated immune escape of diffuse large B-cell lymphoma by targeting PD-L1. Biomed Pharmacother. 2018;98:95-101.

100. Mastroianni J, Stickel N, Andrlova H, Hanke K, Melchinger W, Duquesne S, et al. miR-146a Controls Immune Response in the Melanoma Microenvironment. Cancer Res. 2019;79:183-95.

101. Pyzer AR, Stroopinsky D, Rosenblatt J, Anastasiadou E, Rajabi H, Washington A, et al. MUC1 inhibition leads to decrease in PD-L1 levels via upregulation of miRNAs. Leukemia. 2017;31:2780-90.

102. Wang $X$, Li J, Dong K, Lin F, Long M, Ouyang Y, et al. Tumor suppressor miR-34a targets PD-L1 and functions as a potential immunotherapeutic target in acute myeloid leukemia. Cell Signal. 2015;27:443-52.

103. Xie WB, Liang LH, Wu KG, Wang LX, He X, Song C, et al. MiR-140 Expression Regulates Cell Proliferation and Targets PD-L1 in NSCLC. Cell Physiol Biochem. 2018;46:654-63.

104. Wan J, Ling $X$, Peng B, Ding G. miR-142-5p regulates CD4+ T cells in human non-small cell lung cancer through PD-L1 expression via the PTEN pathway. Oncol Rep. 2018:40:272-82.

105. Jia L, Xi Q, Wang H, Zhang Z, Liu H, Cheng Y, et al. miR-142-5p regulates tumor cell PD-L1 expression and enhances anti-tumor immunity. Biochem Biophys Res Commun. 2017:488:425-31

106. Chen L, Gibbons DL, Goswami S, Cortez MA, Ahn YH, Byers LA, et al. Metastasis is regulated via microRNA-200/ZEB1 axis control of tumour cell PDL1 expression and intratumoral immunosuppression. Nat Commun. 2014;5:5241.
107. Sun C, Lan P, Han Q, Huang M, Zhang Z, Xu G, et al. Oncofetal gene SALL4 reactivation by hepatitis $B$ virus counteracts miR-200C in PD-L1-induced T cell exhaustion. Nat Commun. 2018:9:1241.

108. Wu Q, Zhao Y, Sun Y, Yan X, Wang P. miR-375 inhibits IFN-gamma-induced programmed death 1 ligand 1 surface expression in head and neck squamous cell carcinoma cells by blocking JAK2/STAT1 signaling. Oncol Rep. 2018;39:1461-8.

109. Zhao L, Yu H, Yi S, Peng X, Su P, Xiao Z, et al. The tumor suppressor miR138-5p targets PD-L1 in colorectal cancer. Oncotarget. 2016;7:45370-84.

110. Cioffi M, Trabulo SM, Vallespinos M, Raj D, Kheir TB, Lin ML, et al. The miR25-93-106b cluster regulates tumor metastasis and immune evasion via modulation of CXCL12 and PD-L1. Oncotarget. 2017:8:21609-25.

111. Audrito V, Serra S, Stingi A, Orso F, Gaudino F, Bologna C, et al. PD-L1 upregulation in melanoma increases disease aggressiveness and is mediated through miR-17-5p. Oncotarget. 2017;8:15894-911.

112. Fujita Y, Yagishita S, Hagiwara K, Yoshioka Y, Kosaka N, Takeshita F, et al. The clinical relevance of the miR-197/CKS1B/STAT3-mediated PD-L1 network in chemoresistant non-small-cell lung cancer. Mol Ther. 2015;23:717-27.

113. Abrahams VM, Kamsteeg M, Mor G. The Fas/Fas ligand system and cancer: immune privilege and apoptosis. Mol Biotechnol. 2003;25:19-30.

114. Kim R, Emi M, Tanabe K, Arihiro K. Tumor-driven evolution of immunosuppressive networks during malignant progression. Cancer Res. 2006;66:5527-36.

115. Mariotti B, Calabretto G, Rossato M, Teramo A, Castellucci M, Barila G, et al. Identification of a miR-146b-FasL axis in the development of neutropenia in T large granular lymphocyte leukemia. Haematologica. 2019. https://doi.org/ 10.3324/haematol.2019.225060

116. Xie Z, Chen W, Chen Y, Wang X, Gao W, Liu Y. miR-768-3p is involved in the proliferation, invasion and migration of non-small cell lung carcinomas. Int J Oncol. 2017;51:1574-82.

117. Wu MF, Yang J, Xiang T, Shi YY, Liu L. miR-21 targets Fas ligand-mediated apoptosis in breast cancer cell line MCF-7. J Huazhong Univ Sci Technolog Med Sci. 2014;34:190-4.

118. Wang N, Zhang CQ, He JH, Duan XF, Wang YY, Ji X, et al. MiR-21 downregulation suppresses cell growth, invasion and induces cell apoptosis by targeting FASL, TIMP3, and RECK genes in esophageal carcinoma. Dig Dis Sci. 2013;58:1863-70.

119. Wang P, Zhuang L, Zhang J, Fan J, Luo J, Chen H, et al. The serum miR-21 level serves as a predictor for the chemosensitivity of advanced pancreatic cancer, and miR-21 expression confers chemoresistance by targeting FasL. Mol Oncol. 2013;7:334-45.

120. Wang K, Li PF. Foxo3a regulates apoptosis by negatively targeting miR-21. J Biol Chem. 2010;285:16958-66.

121. Cheong JE, Sun L. Targeting the IDO1/TDO2-KYN-AhR pathway for cancer immunotherapy — challenges and opportunities. Trends Pharmacol Sci. 2018;39:307-25.

122. Gunther J, Dabritz J, Wirthgen E. Limitations and off-target effects of tryptophanrelated IDO Inhibitors in cancer treatment. Front Immunol. 2019;10:1801.

123. Zhu L, Tu H, Liang Y, Tang D. MiR-218 produces anti-tumor effects on cervical cancer cells in vitro. World J Surg Oncol. 2018;16:204.

124. Lou Q, Liu R, Yang X, Li W, Huang L, Wei L, et al. miR-448 targets IDO1 and regulates CD8(+) T cell response in human colon cancer. J Immunother. Cancer. 2019;7:210.

125. Zhou J, Yang Y, Wang W, Zhang Y, Chen Z, Hao C, et al. Melanoma-released exosomes directly activate the mitochondrial apoptotic pathway of CD4(+) T cells through their microRNA cargo. Exp Cell Res. 2018;371:364-71.

126. Ye SB, Li ZL, Luo DH, Huang BJ, Chen YS, Zhang XS, et al. Tumor-derived exosomes promote tumor progression and T-cell dysfunction through the regulation of enriched exosomal microRNAs in human nasopharyngeal carcinoma. Oncotarget. 2014;5:5439-52.

127. Ying $X$, Wu Q, Wu X, Zhu Q, Wang X, Jiang L, et al. Epithelial ovarian cancersecreted exosomal miR-222-3p induces polarization of tumor-associated macrophages. Oncotarget. 2016;7:43076-87.

128. Chen X, Ying X, Wang X, Wu X, Zhu Q, Wang X. Exosomes derived from hypoxic epithelial ovarian cancer deliver microRNA-940 to induce macrophage M2 polarization. Oncol Rep. 2017;38:522-8.

129. Chen $X$, Zhou J, Li X, Wang X, Lin Y, Wang X. Exosomes derived from hypoxic epithelial ovarian cancer cells deliver microRNAs to macrophages and elicit a tumor-promoted phenotype. Cancer Lett. 2018;435:80-91.

130. Hsieh CH, Tai SK, Yang MH. Snail-overexpressing cancer cells promote M2like polarization of tumor-associated macrophages by delivering MiR-21Abundant exosomes. Neoplasia. 2018;20:775-88. 
131. Cooks T, Pateras IS, Jenkins LM, Patel KM, Robles Al, Morris J, et al. Mutant p53 cancers reprogram macrophages to tumor supporting macrophages via exosomal miR-1246. Nat Commun. 2018;9:771.

132. Jang JY, Lee JK, Jeon YK, Kim CW. Exosome derived from epigallocatechin gallate treated breast cancer cells suppresses tumor growth by inhibiting tumorassociated macrophage infiltration and M2 polarization. BMC Cancer. 2013;13:421.

133. Ren W, Zhang X, Li W, Feng Q, Feng H, Tong Y, et al. Exosomal miRNA-107 induces myeloid-derived suppressor cell expansion in gastric cancer. Cancer Manag Res. 2019;11:4023-40.

134. Li L, Cao B, Liang X, Lu S, Luo H, Wang Z, et al. Microenvironmental oxygen pressure orchestrates an anti- and pro-tumoral gammadelta T cell equilibrium via tumor-derived exosomes. Oncogene. 2019;38:2830-43.

135. Guo X, Qiu W, Liu Q, Qian M, Wang S, Zhang Z, et al. Immunosuppressive effects of hypoxia-induced glioma exosomes through myeloid-derived suppressor cells via the miR-10a/Rora and miR-21/Pten Pathways. Oncogene. 2018;37:4239-59.

136. Guo X, Qiu W, Wang J, Liu Q, Qian M, Wang S, et al. Glioma exosomes mediate the expansion and function of myeloid-derived suppressor cells through microRNA-29a/Hbp1 and microRNA-92a/Prkarla pathways. Int J Cancer. 2019;144:3111-26.

137. Bruns H, Bottcher M, Qorraj M, Fabri M, Jitschin S, Dindorf J, et al. CLL-cellmediated MDSC induction by exosomal miR-155 transfer is disrupted by vitamin D. Leukemia. 2017;31:985-8.

138. Wang J, Guan X, Zhang Y, Ge S, Zhang L, Li H, et al. Exosomal miR-27a Derived from Gastric Cancer Cells Regulates the Transformation of Fibroblasts into Cancer-Associated Fibroblasts. Cell Physiol Biochem. 2018:49:869-83.

139. Fang T, Lv H, Lv G, Li T, Wang C, Han Q, et al. Tumor-derived exosomal miR1247-3p induces cancer-associated fibroblast activation to foster lung metastasis of liver cancer. Nat Commun. 2018;9:191.

140. Zhou Y, Ren H, Dai B, Li J, Shang L, Huang J, et al. Hepatocellular carcinoma-derived exosomal miRNA-21 contributes to tumor progression by converting hepatocyte stellate cells to cancer-associated fibroblasts. J Exp Clin Cancer Res. 2018:37:324.

141. Fanini F, Fabbri M. Cancer-derived exosomic microRNAs shape the immune system within the tumor microenvironment: State of the art. Semin Cell Dev Biol. 2017;67:23-8.

142. Yang L, Zhang Y. Tumor-associated macrophages: from basic research to clinical application. J Hematol Oncol. 2017;10:58.

143. Brown JM, Recht L, Strober S. The promise of targeting macrophages in cancer therapy. Clin Cancer Res. 2017;23:3241-50.

144. Tian X, Shen H, Li Z, Wang T, Wang S. Tumor-derived exosomes, myeloidderived suppressor cells, and tumor microenvironment. J Hematol Oncol. 2019;12:84.

145. Truffi M, Mazzucchelli S, Bonizzi A, Sorrentino L, Allevi R, Vanna R, et al. Nano-Strategies to Target Breast Cancer-Associated Fibroblasts: Rearranging the Tumor Microenvironment to Achieve Antitumor Efficacy. Int J Mol Sci. 2019. https://doi.org/10.3390/ijms20061263.

146. Cortez MA, Ivan C, Valdecanas D, Wang X, Peltier HJ, Ye Y, et al. PDL1 Regulation by p53 via miR-34. J Natl Cancer Inst. 2016. https://doi.org/10.1093/jnci/djv303.

147. Zhang PF, Pei X, Li KS, Jin LN, Wang F, Wu J, et al. Circular RNA circFGFR1 promotes progression and anti-PD-1 resistance by sponging miR-381-3p in non-small cell lung cancer cells. Mol Cancer. 2019;18:179.

148. Nakahara S, Fukushima S, Okada E, Morinaga J, Kubo Y, Tokuzumi A, et al. MicroRNAs that predict the effectiveness of anti-PD-1 therapies in patients with advanced melanoma. J Dermatol Sci. 2020;97:77-9.

149. Zheng Z, Sun R, Zhao HJ, Fu D, Zhong HJ, Weng XQ, et al. MiR155 sensitized B-lymphoma cells to anti-PD-L1 antibody via PD-1/PD-L1-mediated lymphoma cell interaction with CD8+T cells. Mol Cancer. 2019;18:54.

150. Huber V, Vallacchi V, Fleming V, Hu X, Cova A, Dugo M, et al. Tumor-derived microRNAs induce myeloid suppressor cells and predict immunotherapy resistance in melanoma. J Clin Invest. 2018:128:5505-16.

151. Zhang T, Zhang Z, Li F, Ping Y, Qin G, Zhang C, et al. miR-143 Regulates Memory T Cell Differentiation by Reprogramming T Cell Metabolism. J Immunol. 2018;201:2165-75.

152. Liang G, Zhu Y, Ali DJ, Tian T, Xu H, Si K, et al. Engineered exosomes for targeted co-delivery of miR-21 inhibitor and chemotherapeutics to reverse drug resistance in colon cancer. J Nanobiotechnology. 2020;18:10.

\section{Publisher's Note}

Springer Nature remains neutral with regard to jurisdictional claims in published maps and institutional affiliations.

Ready to submit your research? Choose BMC and benefit from:

- fast, convenient online submission

- thorough peer review by experienced researchers in your field

- rapid publication on acceptance

- support for research data, including large and complex data types

- gold Open Access which fosters wider collaboration and increased citations

- maximum visibility for your research: over $100 \mathrm{M}$ website views per year

At BMC, research is always in progress.

Learn more biomedcentral.com/submissions 